\title{
Analysis of a Support Base Stand using Finite Element Analysis
}

\author{
- \\ A. Muhammad ${ }^{1 *}$ I. H. Shanono ${ }^{2}$ \\ ${ }^{1}$ Department of Mechatronics Engineering, Bayero University, Kano, Nigeria. \\ ${ }^{2}$ Department of Electrical Engineering, Bayero University, Kano, Nigeria.
}

ABSTRACT: In this paper, deformation, Von-Mises stress, and failure analysis were carried out on a base stand using ANSYS workbench. The structural design was carried out using SolidWorks software and then imported into the ANSYS workbench for analysis. The investigation is performed using four different materials, i.e., structural steel, aluminum alloy, carbon fiber, and copper alloy, with an applied loading force of $1000 \mathrm{~N}$ at the tip of the structure. This technique highlights a complete reaction of the structure to the loading force, therefore providing room for structural optimization to reduce the risk of unexpected failure and unnecessary material wastage. The results obtained were compared and analyzed to identify the best material capable of withstanding the subjected force. Based on the Von-mises result, Carbon fiber has the highest possible maximum stress value of $4.70 \mathrm{e}+07 \mathrm{~Pa}$, followed by structural steel, then Copper alloy. At the same time, the aluminium alloy has the least minimum Von-Mises. Structural steel is the very best option based upon the analysis outcomes. Its factor of safety is above unity in all the designs, which indicates that the structure has been over-designed. For that reason, it is suggested that the structure needs to be enhanced.

KEYWORDS: Finite element analysis, base stand, ANSYS, deformation, von mises stress.

[Received Sept. 3, 2019; Revised Feb. 10, 2021; Accepted Feb. 17, 2021]

Print ISSN: 0189-9546 | Online ISSN: 2437-2110

\section{INTRODUCTION}

A base stand is a structurally designed pedestal for holding or supporting an object in a specific desired position. The weight of the object it supports can be classified as a lightweight or heavy-duty base stand, which could be used for domestics or industrial applications. Its application and operating conditions are the vital factors considered by the production companies to maximize profits without compromising product quality and reliability. These factors range from environmental, stress, and loading properties, etc., which are used to determine the base stand shape, weight, size, and the type of material used for production. Base stands are used for establishing a versatile system of base stands, enabling upright rods to be screwed in and straight rods to be spanned in between (United States Patent No. 5,220,740, 1993). Usual merchandise displays racks or Stands commonly include a central upright rod for connecting numerous display devices such as carousels, hooks, baskets, or shelves. The upright pole and also screen device of these devices are sustained off the ground by a base. Base stands are typical of the disc-type or leg-type (United State Patent No. US 6,367,749 B2, 2002).

A selection of base stands that can build a solid structure for support of equipment and instruments is readily available. The standard base stand used for basic applications have a base made of steel and also a black enamel surface, provided with a

*Corresponding author: ayshermuhd@gmail.com detachable zinc layered steel rod, while Heavy Support Base Stands have an included steel plate that adds 50\% more weight than the standard variation as well as a more deeply threaded rod hole for more stability, supplied with a detachable zinc layered steel rod (Scientific, 2021).

Stanley (United State Patent No. US 6,367,749 B2, 2002) gives a base stand comprising a central hub and a plurality of removable legs affixed to the central hub. Each of the legs expands radially external and downwardly from the main hub. The base stand is adjusted to receive a display shelf's central vertical support and give lateral and upright support. The plurality of legs might be removed from the central center and packaged in a nested configuration that is portable for shipping and storage. Each of the legs' plurality has an arcuate shape to ensure that the plurality of legs supply a natural resiliency and upward predisposition when a load is placed on it. The base supplies support in either a normal or high load setting for boosted vertical and side support of the shelf (United State Patent No. US 6,367,749 B2, 2002).

Finite Element Analysis (FEA) involves the simulation of a physical engineering structure using a numerical technique called Finite Element Method (FEM). It consists of subdividing the structure into smaller elements called mesh. Several numbers of design analyses under different constraints are performed with FEA (Muhammad and Shanono, 2019). In designing a complex structure, computer-aided design (CAD) is used. Then the analysis is performed using Computer-aided 
engineering (CAE) software such as ANSYS, which is the most widely used software amongst others.

Further investigation can also be done to improve the design for optimal performance and lifespan regarding design failure (Chen, 2014). ANSYS Workbench has a user-friendly platform. It provides two-way access to the most used computer-aided design systems.

The solid modeling software defines the geometry of the solid structure. The meshing of the elements of the structure is done using the ANSYS workbench. For a more accurate result, finer meshing sizes are used. The design constraints are applied in this study, and then finally, the simulation results are retrieved after being solved by the ANSYS software (Qiongying, 2014; Muhammad and Shanono, 2019).

In load application requirements, support stands need to have a higher maximum load capacity than needed to raise or sustain an object(s). For ideal constant performance, a base stand should have a maximum load capacity which is a lot more than the operating load, so that stresses do not destroy the support with time (GlobalSpec, 2021).

This study analyzes the deformation, stress (Von-Mises), and failure of a base stand. The analysis is carried out in ANSYS static structural, mechanical solver with a tensile force of $1000 \mathrm{~N}$ in (assuming 100kg load capacity) acting downwards (Y-direction) along the three legs of the fixed positioned base stand. The analysis was conducted on structural steel, aluminum alloy, carbon fiber, and copper alloy to get the most suitable material for the desired application.

\section{A. Finite Element Method}

\section{MATERIALS AND METHODS}

A numerical method for solving a problem to an approximately exact solution described by partial differential equations is FEM (Chen, 2014). FEM is used to solve the problem by subdividing the engineering structure into smaller elements. An excellent, desirable feature of FEM is its ability to deal with complex engineering structures and constraints. The procedure and steps used in solving the problem using the FEM approach are depicted in Figure 1 (Muhammad and Shanono, 2018a; Muhammad and Shanono, 2018b).

\section{B. Finite Element Analysis using ANSYS}

After the structure's CAD design is done using Solid-Works software, it is then exported into ANSYS workbench for analysis. Analysis of any structure begins with the geometry definition, which is defined based on the type of simulation analysis that is to be carried out. Since our study focuses on stress and deformation, the exact FEA model used is a substructure. There are two main ways of introducing a threedimensional structure into ANSYS software. First is by saving it as an Initial Graphics Exchange Specification(IGES) format then import it into the ANSYS workbench, the second method is by building the entire structure in the ANSYS workbench (Guanzhuer et al., 2012; Kim et al., 2007; Janq et al., 2002).

In this paper, the analysis is performed via geometry cell by importing the geometry from a CAD in the IGES format into the software. The hub is $35 \mathrm{~mm}$ from the ground level and 18 $\mathrm{mm}$ tall. The holder is $36 \mathrm{~mm}$ long with a 6 and $3 \mathrm{~mm}$ radius for the holder and pin, respectively, as shown in Figure 2.

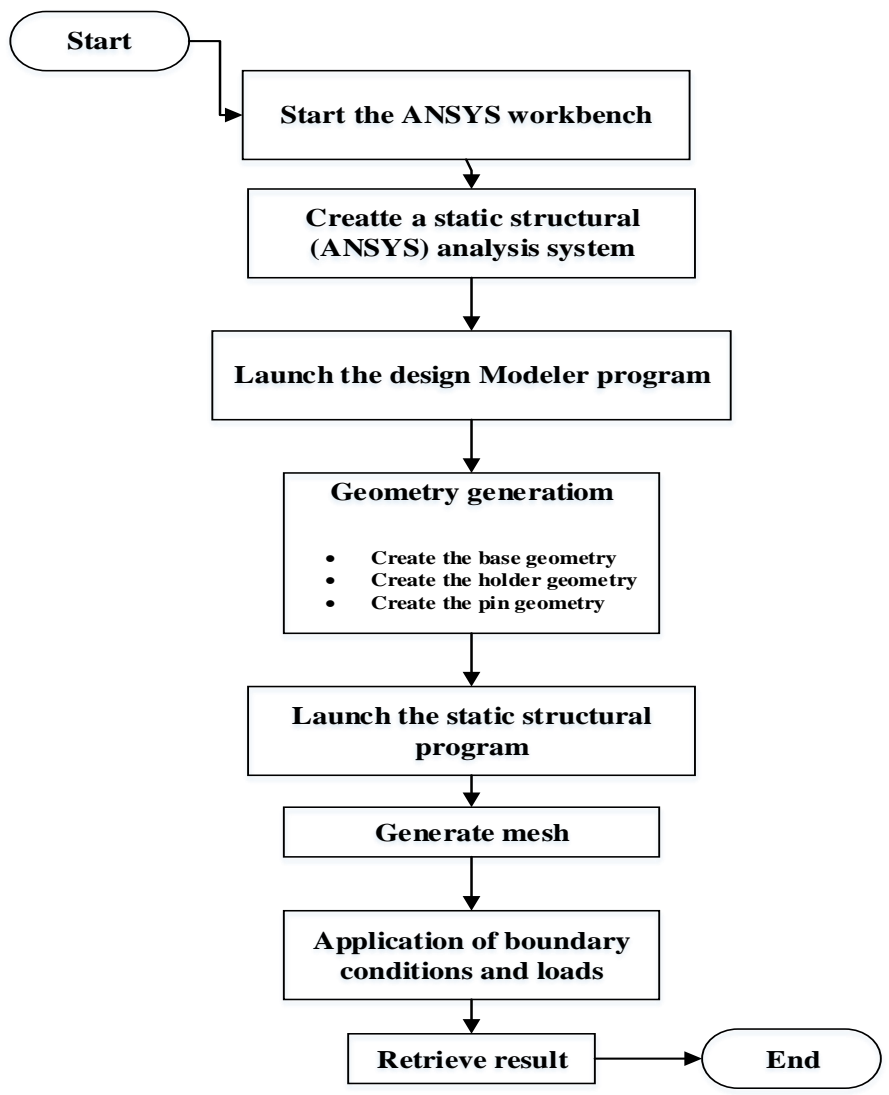

Figure 1: FEA flowchart.

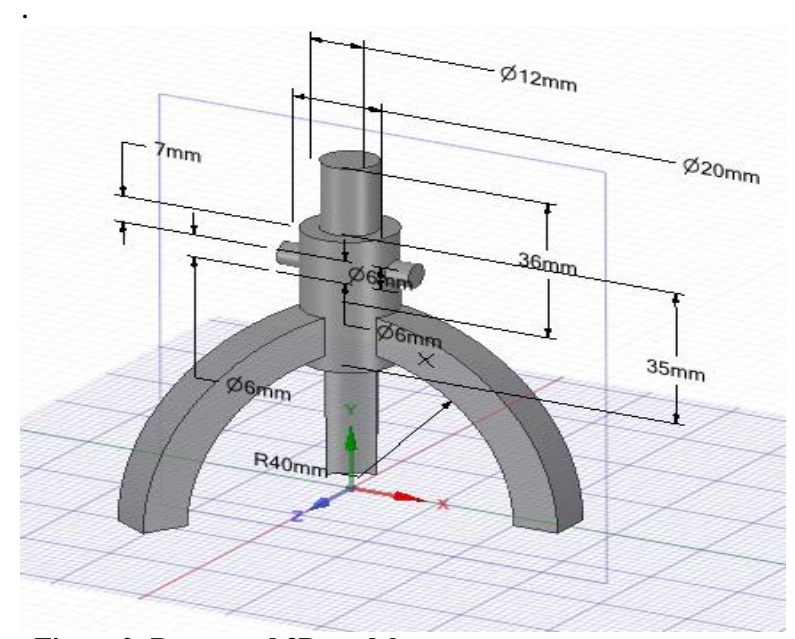

Figure 2: Base stand 3D model.

Material properties are defined based on the type of simulation analysis to be performed. For efficient and qualitative analysis of the material, the material properties need to be correctly and carefully entered after creating the engineering data material. These materials, which can be either linear or nonlinear, isotropic or orthotropic, constant or temperature-dependent, need to be defined correctly. 
Depending on the analysis's aim, some mechanical properties such as density, strength, and coefficient of thermal expansion definition are optional (Barbero, 2014). Knowing and declaring the correct value of the material property is very useful for design analysis purposes. The different types of material indicated by different densities will show different analysis result outcomes as well (Muhammad and Shanono, 2019).

The Young's modulus of a material alternatively called modulus of elasticity is a numerical constant that describes the elasticity and measures a solid's capability to withstand changes when subjected to tension or compression in a specific direction. The higher Young's modulus, the stiffer (i.e., how it deflects under load) is the material that will require a much higher amount of load to deform. Poisson's ratio, which is the ratio of compression to the expansion of the material, and

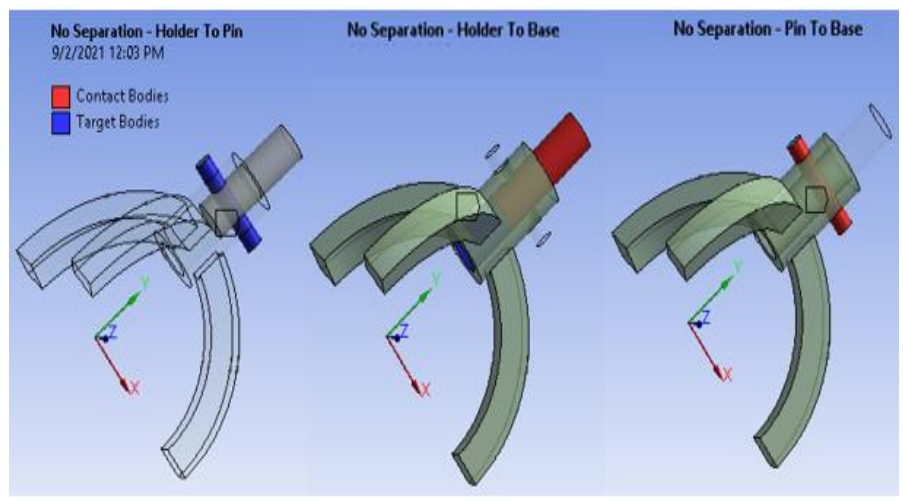

Figure 3. Contact type definition. Young's modulus (ratio of stress to strain), defines the strength and nature of how a material structure deforms based on a particular constraint.

Table 1: Properties of materials.

\begin{tabular}{lllll}
\hline Material Type/ Property & \multicolumn{1}{c}{ Structural steel } & Aluminium alloy & Carbon fibre & Copper alloy \\
\hline Young's Modulus & $2 \mathrm{E}+11 \mathrm{~Pa}$ & $7.1 \mathrm{E}+10 \mathrm{~Pa}$ & $1 \mathrm{E}+11 \mathrm{~Pa}$ & $1.1 \mathrm{E}+11 \mathrm{~Pa}$ \\
Density & $7850 \mathrm{kgm}^{\wedge}-3$ & $2770 \mathrm{kgm}^{\wedge}-3$ & $1600 \mathrm{kgm}^{\wedge}-3$ & $8300 \mathrm{kgm}^{\wedge}-3$ \\
Poisson's ratio & 0.30 & 0.33 & 0.10 & 0.34 \\
Bulk modulus & $1.6667 \mathrm{E}+11 \mathrm{~Pa}$ & $6.9608 \mathrm{E}+10 \mathrm{~Pa}$ & $4.1667 \mathrm{E}+10 \mathrm{~Pa}$ & $1.1458 \mathrm{E}+11 \mathrm{~Pa}$ \\
Shear Modulus & $7.6923 \mathrm{E}+10 \mathrm{~Pa}$ & $2.6692 \mathrm{E}+10 \mathrm{~Pa}$ & $4.5455 \mathrm{E}+10 \mathrm{~Pa}$ & $4.1045 \mathrm{E}+10 \mathrm{~Pa}$ \\
Tensile strength & $2.5 \mathrm{E}+08 \mathrm{~Pa}$ & $2.8 \mathrm{E}+08 \mathrm{~Pa}$ & $75.85 \mathrm{~N} / \mathrm{mm}^{\wedge} 2$ & $2.8 \mathrm{E}+08 \mathrm{~Pa}$ \\
Ultimate shear strength & $4.6 \mathrm{E}+08 \mathrm{~Pa}$ & $3.1 \mathrm{E}+08 \mathrm{~Pa}$ & $600 \mathrm{MPa}$ & $4.3 \mathrm{E}+08 \mathrm{~Pa}$ \\
\end{tabular}

Material deformation due to uniform volume and opposing forces are described by the bulk and shear modulus. Two other essential properties that determine when the material losses its elastic behavior and the maximum stress a material can undergo are the yields and tensile strength, respectively (Nipun, 2015; Muhammad and Shanono, 2018).

After importing the geometry, the definition of the element and material properties is carried out. Each material used has seven essential properties useful in the analysis and is obtained from the ANSYS tool's engineering data source. Table 1 below presents those properties. A no-separation contact condition is assumed for all contact regions: Holder to pin, holder to base, and pin to base, as shown in Figure 3. This allows movement of each part relative to the other while keeping contact and avoiding a gap.

The breaking down of model or structure into smaller elements to analyze each component is known as meshing (Basavaraj et al., 2016). It is a discrete realization of the structure, which helps solve the exact model solutions (Muhammad and Shanono, 2018).
For a smaller meshing size, the computational time is higher, so the accuracy of the analysis results (Qiongying, 2014). The classification of meshing tools in ANSYS are:

- Unit size control

- Level control of the intelligent division

- Thinning grid control

- Shape settings of meshing

- Grid partition.

Considering the setup time and computational expense, with the speed and ease of use, a free mesh type is used. The default meshing control is used, having a relevance value of +100 with a medium smoothing number of iteration.

Using Table 1, the model properties are set in the software, followed by dividing the structure or model into a finer number of nodes and elements. The meshing size is set to default as determined by the ANSYS software. Figure 4 shows the meshed structure of the base stand. 


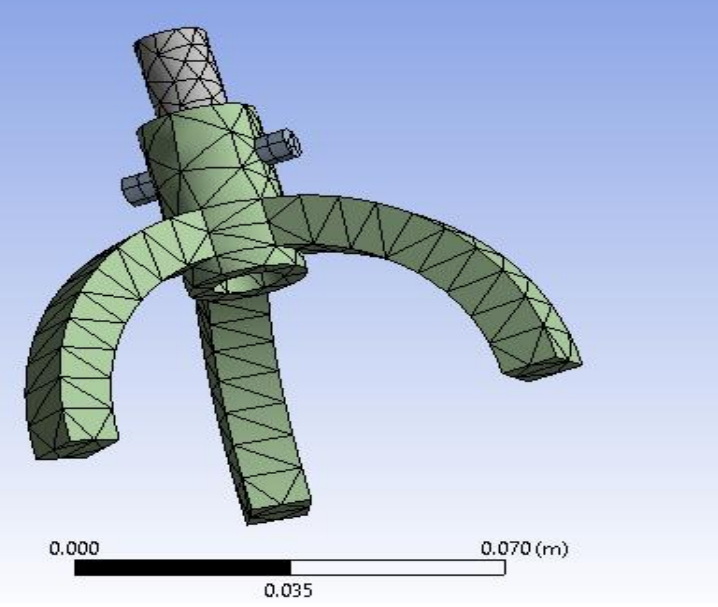

Figure 4: Meshed structure.

Constraints such as fixed support and forces are applied to the model after the meshing is done; this is very important and serves as a primary step required in the analysis (Basavaraj et al., 2016). Constraints are set to conform to real-life situations (Guanzhuet al., 2012; Muhammad and Shanono, 2019). The boundary condition used in this analysis includes support and loads. The support type used for the 3D structure is the fixed support that prevents movement or deformation of the structure geometry. The type of load used is a static force. The based stand is set fixed on its three base legs while a tensile force of $1000 \mathrm{~N}$ is applied to the top holder face, as shown in Figure 5.

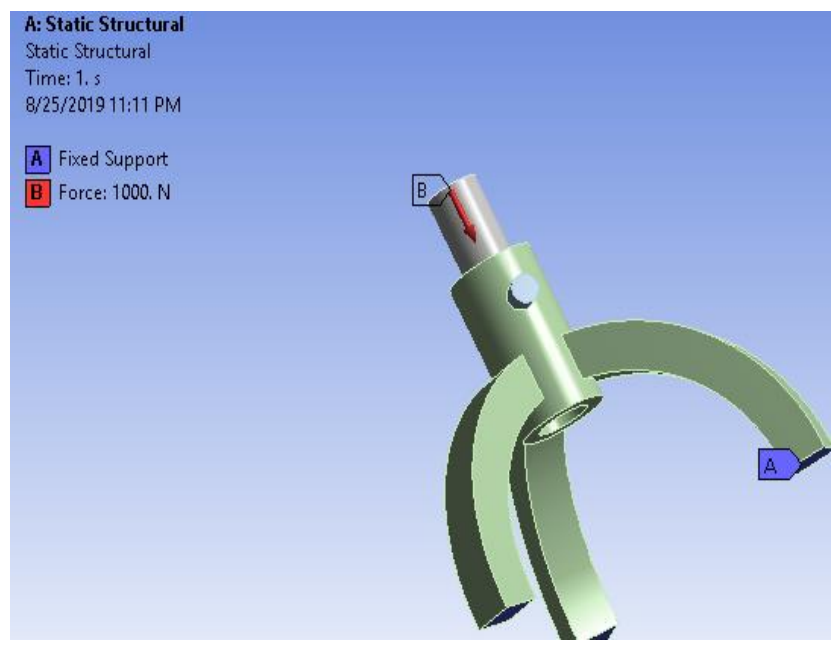

Figure 5: Constraints application.

\section{RESULTS AND DISCUSSION}

Due to the unexpected failure of engineering structures, analysis becomes very significant to ascertain these structures' safety. Such failures or deformations when exposed to loads over a specific duration of time result in the structure's sudden collapse. Hence, this work assesses the deformation, VonMises stress, and safety factor of a base stand model against different materials. Under the current constraints, the analysis results are shown in Figure 6.

To assess the reason for failure, how and where it occurs, and how to prevent it, simulation in Finite Element analysis is done. Therefore, a fundamental goal of performing the analysis is determining a safer design. Failure of the whole or part of the structure leads to a high risk of life and financial loss. Just like in the human context, when the human body does much work, it becomes stressed, sick, and finally, a nervous breakdown may occur. Also, in an engineering structure, failure may occur when a structure is subjected to a high stress level. The amount of pressure in an engineering model that happens when it is exposed to external force or load is termed as stress, which indicates that the applied load is a function of the amount of stress.

Von Mises stress analysis is used to ascertain the failure of his design structure. Failure is inevitable when the strength of the material used is less than the stress's maximum value. VonMises stress is ideally used for ductile materials. The safety factor is the ratio of material strength to the maximum stress in a structure. It describes the load-carrying ability of a structure to the actual loads. Designers use it in assessing if a design is safe. It indicates that the stress of a point in a structure or model is higher than the material strength. The calculation of the safety factor involves the yield strength; therefore, it becomes necessary to declare this parameter before the material properties' simulation.

Below are the results obtained for structural steel material. Figure 6(a) shows the deformation plot when the base stand is subjected to the required load. The maximum deformation stands at $6.7695 \mathrm{e}-006 \mathrm{~m}$ which is indicated by the red color at the holder's tip and the minimum deformation of OPa located at the base legs. The next image (6(b)) shows the stress distribution level across the base stand surface. There appeared to have no overstressed visible region. Figure 6(c) to 6(f) depicts the pin and hole deformations and stress, respectively. The pin maximum deformation and stress occur at the center region, which is the point of contact with the holder hole. Similarly, the holder displays maximum deformation at its tip and maximum stress at the vicinity of contact with the pin.

Figure $6(\mathrm{~g})$ is the safety factor (SF) level, which shows that no region of the material is overstressed; most of it lies within the maximum SF level of 15. 


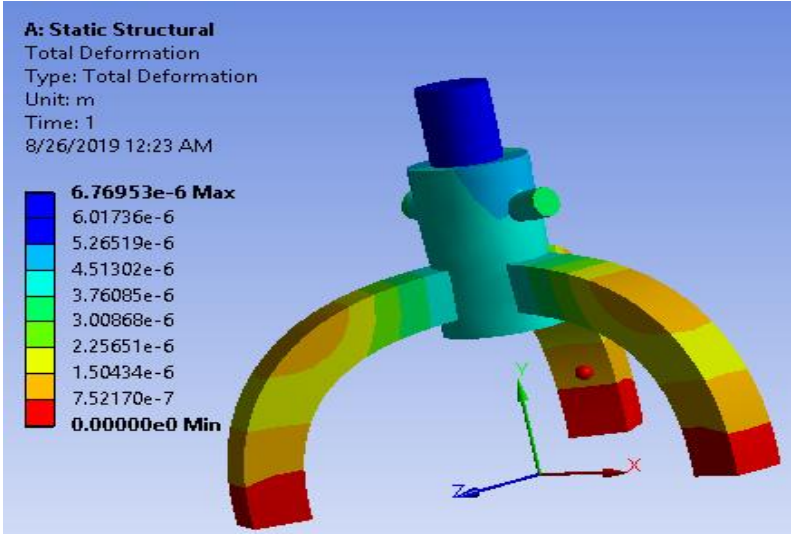

(a)

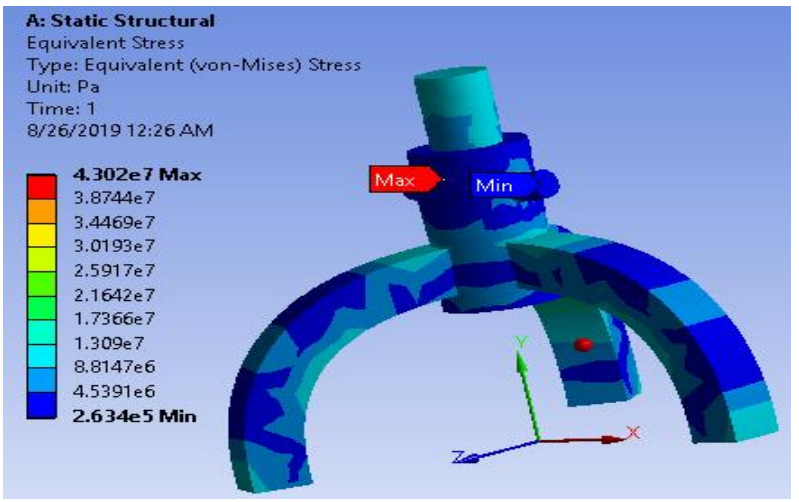

(b)
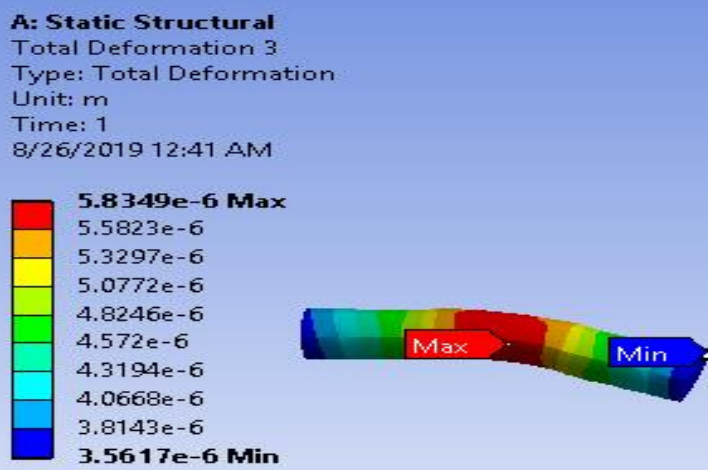

(c)

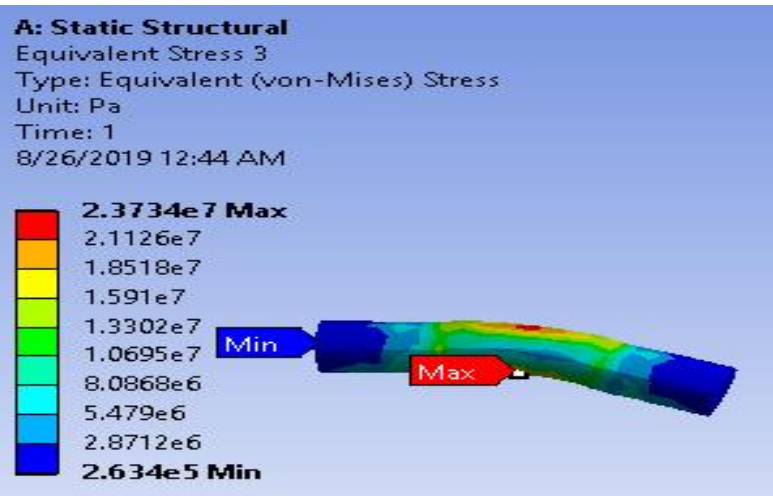

(d)

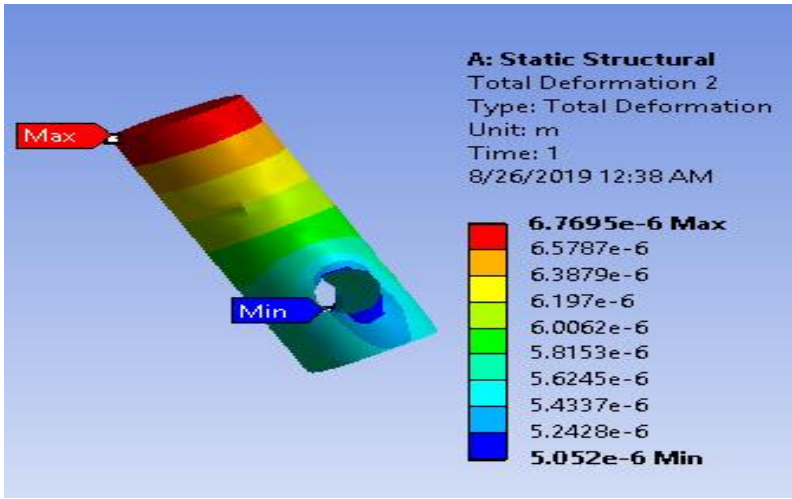

(e)

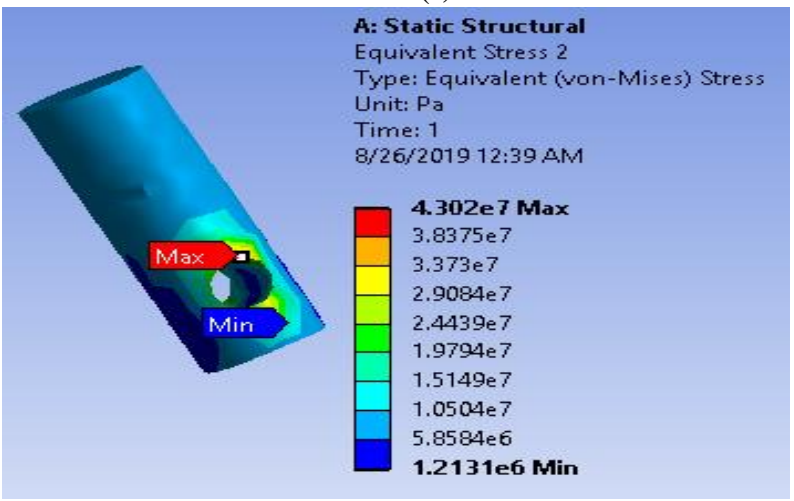

(f)

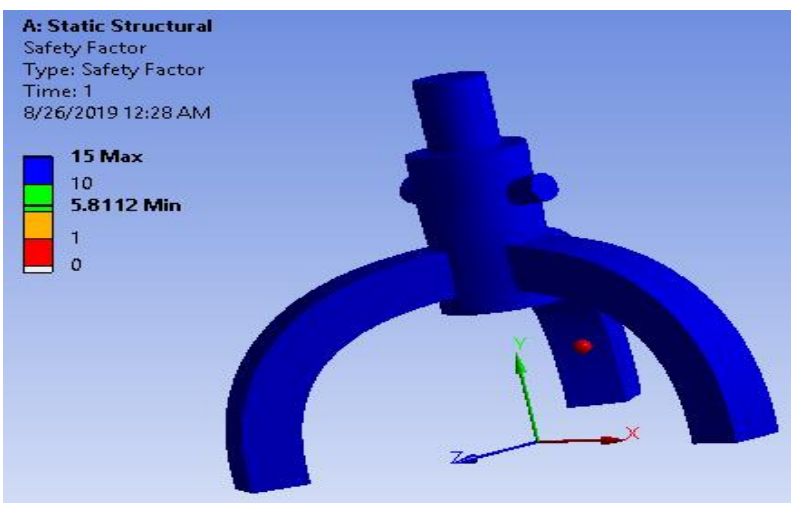

(g)

Figure 6: (a) Base Total deformation (b) Base Equivalent stress(c) Pin Total deformation (d) Pin Equivalent stress (e) Holder total deformation (f) Holder equivalent stress (g) Safety factor.

When Aluminum alloy was used as the structural material, there appeared some significant changes compared to the use of steel as the structural material, even though it was subjected to the same loading force. A maximum deformation and stress of $1.541 \mathrm{e}-005 \mathrm{~m}$ and $1.4019 \mathrm{e}+007 \mathrm{~Pa}$ occurred at the same points as the previous material, respectively. The pin and the holder were also analyzed, indicating the maximum and minimum deformation and stress level, which suggests that the applied external stress is higher than the material strength. Therefore it is not safe to use such material under such load. The structure has a safety factor above unity. For a carbon fiber material, the same factors were used, indicating that the minimum SF to lies within the range of 5-10 at the holder tip and base legs with $1.3683 \mathrm{e}-005 \mathrm{~m} \mathrm{4.6992e+007} \mathrm{Pa} \mathrm{values} \mathrm{of}$ 
deformation and stress, respectively. Lastly, copper alloy is used as the material. The obtained deformation, stress, and safety factor received indicates that the material strength can withstand the maximum applied stress, making it safe to be used in the application.

The deformation and Von-mises stress for the four sets of materials are graphically compared, as shown in Figures 7 (ad).

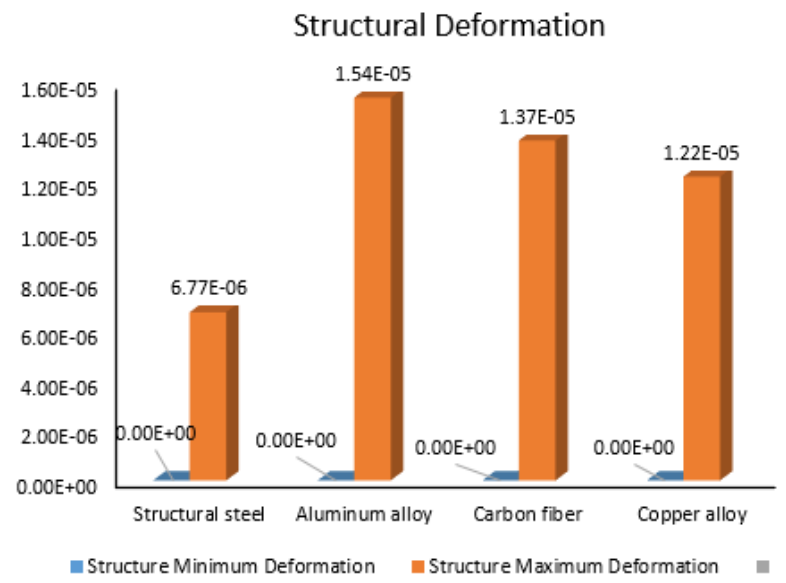

(a)

\section{Structural Von-Mises stress}

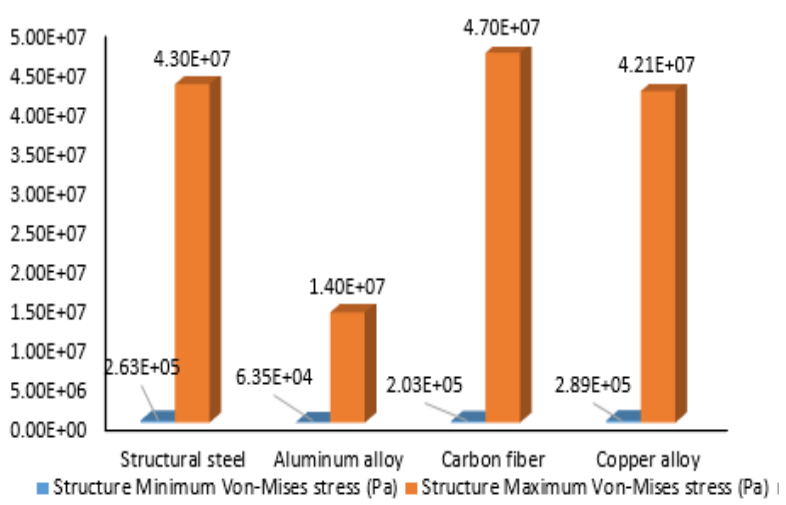

(b)

Pin \& Holder Maximum Deformation

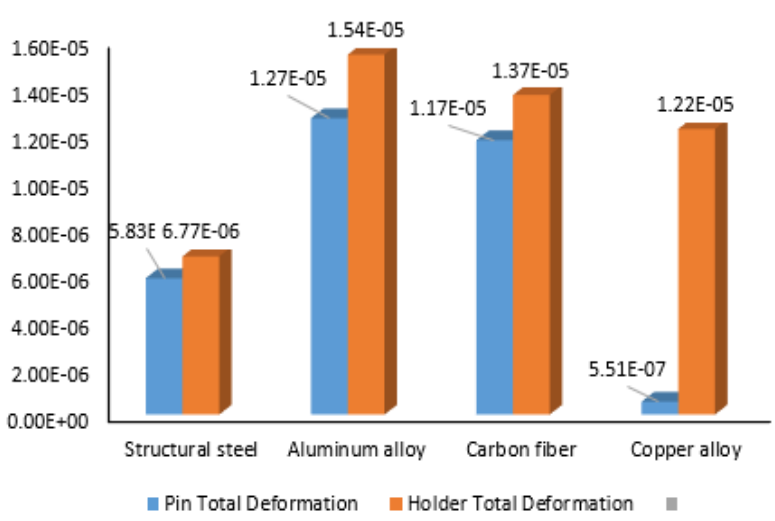

(c)

\section{Pin \& Holder Maximum stress}

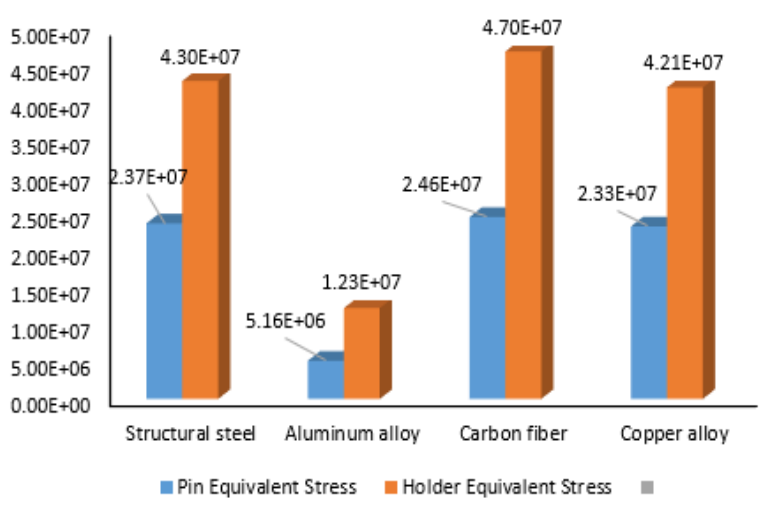

(d)

Figure 7: (a) Structural deformation (b) Structural equivalent stress (c) Pin and Holder deformation (d) Pin and holder stress.

\section{CONVERGENCE HISTORY}

Further repeated refinement of the FEA structure into much smaller elements results in the convergence of the solution to an exact solution of the mathematical problem. Some of these refinement types formulated in FEA which converges the FEA solution to an exact solution of the mathematical model include h-refinement (with $\mathrm{h}$ referring to the element size), p-refinement (preferring to the polynomial highest order), r-refinement (which rearrange the nodes in the mesh) and hp-refinement (which combines $h$ and p-refinement) (Chen, 2014). In this analysis, the convergence criteria are based on the total deformation with a $1 \%$ tolerance limit. Convergence was obtained for the static analysis solution after a maximum number of 10 refinement loops, as shown in Figure 8. Maximum total deformations that result at different mesh iteration are displayed and shown in Table 2.

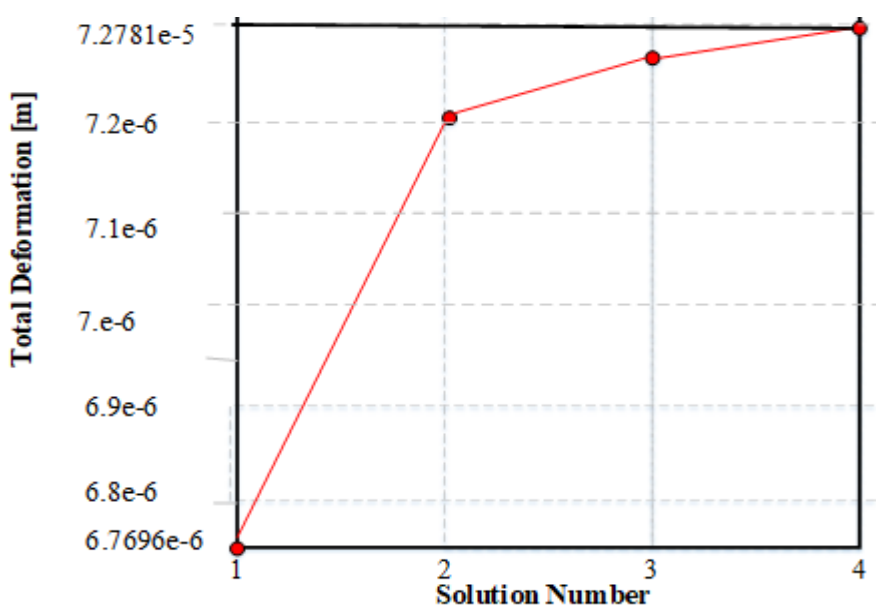

(a) 


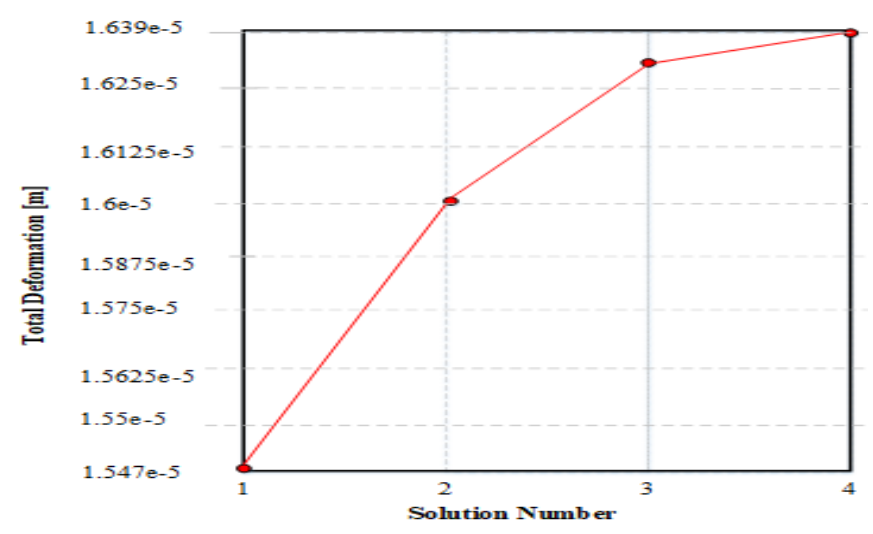

(b)

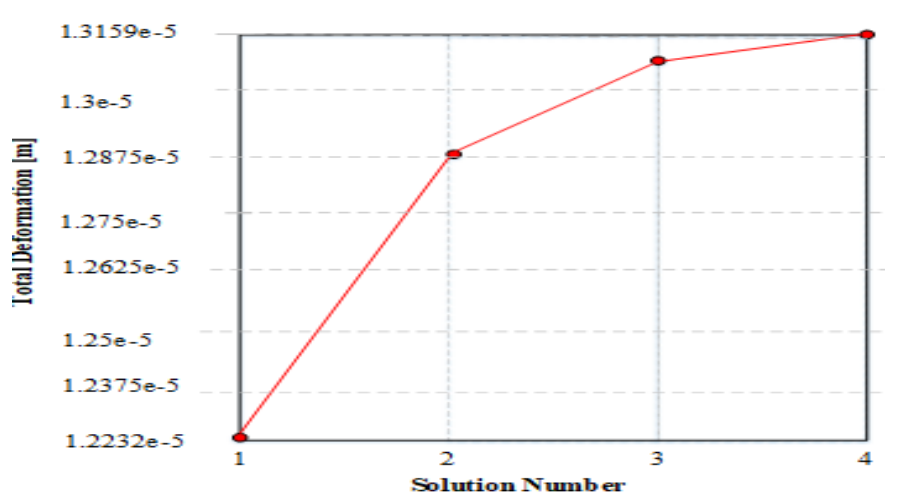

(c)

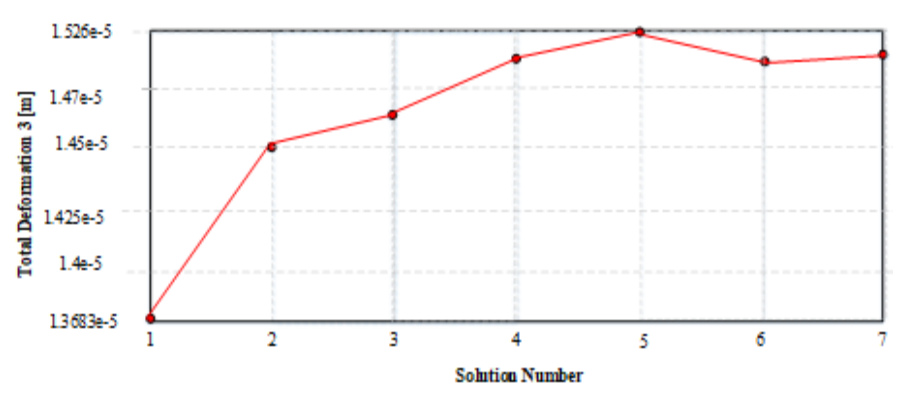

(d)

Figure 8(a) Structural steel (b) Aluminum (c) Copper (d) Carbon.

\section{CONCLUSION}

In this study, failure analysis using Finite Element Method (FEM) in ANSYS workbench was carried out on a support base stand under certain design constraints. The base structure was imported into the ANSYS software as an IGES file after its design in Solidworks software. The Von mises stress analysis obtained; carbon fiber had the highest value of 4.70e+07Pa maximum stress, followed by steel, copper alloy, and aluminum alloy. All the maximum Von Mises stress in the material structures are less than the material tensile and ultimate shear stress, indicating that the applied stress is less than the material yield point value. The safety factors obtained for all the materials appeared to have enough safety band except aluminum alloy that has a value greater than unity.

Lastly, structural steel is the best choice based on the results obtained. The safety factor is far superior to unity in all the models, which indicates that the structure has been overengineered. The materials are too excessive, and this shows wastage of resources and cost. Therefore, it is recommended that the structure should be optimized. This paper introduces FEM for similar engineering structures and gives away future studies for structural optimization. To accurately figure out the failure of a support base stand, numerous pieces of information are required. An even more thorough examination would be very beneficial. As a future recommendation, combining simulations as well as speculative could be used to get a much more precise understanding.

\section{REFERENCES}

Basavaraj, T.; S. N. Kurbet.; Kuppast, V. V., Arvind. (2016). Harmonic analysis of a two-cylinder crankshaft using ANSYS. 2016 International Conference on Inventive Computation Technologies (ICICT) (pp. 1-6). Coimbatore, India: IEEE. doi:10.1109/INVENTIVE.2016.7823219.

Barbero, E. J. (2014). Finite Element Analysis of Composite Materials Using ANSYS. US: CRC Press, Tylor and Francis group.

Bertrand, W. B.; and Q. Warwick. (1993). United States Patent No. 5,220,740.

GlobalSpec. (2021). (Engineering360) Retrieved 7/2/ 2021,https://www.globalspec.com/learnmore/material_handli ng_packaging_equipment/material_handling_equipment/stan ds_supports

Table 2: Mesh iteration table.

\begin{tabular}{|c|c|c|c|c|c|}
\hline Material type & Solution number & Total deformation & Change [\%] & Nodes & Elements \\
\hline \multirow{4}{*}{ Structural steel } & 1 & $6.77 \mathrm{E}-06$ & & 2273 & 915 \\
\cline { 2 - 6 } & 2 & $7.02 \mathrm{E}-06$ & 6.1169 & 11640 & $6.64 \mathrm{E}+03$ \\
\cline { 2 - 6 } & 3 & $7.25 \mathrm{E}-06$ & 0.71455 & 47255 & 30350 \\
\cline { 2 - 6 } & 4 & $7.28 \mathrm{E}+06$ & 0.40977 & 69672 & 45754 \\
\hline \multirow{4}{*}{ Aluminum } & 1 & $1.54 \mathrm{E}-05$ & & 2273 & 915 \\
\cline { 2 - 6 } & 2 & $1.60 \mathrm{E}-05$ & 3.6221 & 10965 & 6085 \\
\cline { 2 - 6 } & 3 & $1.63 \mathrm{E}-05$ & 2.0181 & 45171 & 28522 \\
\cline { 2 - 6 } & 4 & $1.64 \mathrm{E}-05$ & 0.39121 & 118304 & 78931 \\
\hline \multirow{6}{*}{ Copper } & 1 & $1.22 \mathrm{E}-05$ & & 2273 & 915 \\
\cline { 2 - 6 } & 2 & $1.30 \mathrm{E}-05$ & 5.9419 & 11640 & 6637 \\
\cline { 2 - 6 } & 3 & $1.31 \mathrm{E}-05$ & 0.97735 & 47505 & 30521 \\
\hline \multirow{5}{*}{ Carbon } & 4 & $1.32 \mathrm{E}-05$ & 0.38327 & 70128 & 46058 \\
\cline { 2 - 6 } & 1 & $1.37 \mathrm{E}-05$ & & 2273 & 915 \\
\cline { 2 - 6 } & 2 & $1.45 \mathrm{E}-05$ & 5.6218 & 11405 & 6498 \\
\cline { 2 - 6 } & 3 & $1.46 \mathrm{E}-05$ & 1.1259 & 38424 & 24535 \\
\cline { 2 - 6 } & 4 & $1.49 \mathrm{E}-05$ & 1.7006 & 85533 & 56310 \\
\cline { 2 - 6 } & 5 & $1.50 \mathrm{E}-05$ & 0.91879 & 205681 & 139809 \\
\cline { 2 - 6 } & 6 & $1.48 \mathrm{E}-05$ & -1.2307 & 249490 & 170689 \\
\cline { 2 - 6 } & 7 & $1.49 \mathrm{E}-05$ & 0.26973 & 346247 & 238354 \\
\hline
\end{tabular}


Janq, G.H.; S. H. Lee.; M. S. Jung. (2002). Free vibration analysis of a spinning flexible disk-spindle system supported by ball bearing and flexible shaft using the finite element method and substructure synthesis. Journal of Sound and Vibration, 251(1), 59-78. doi:https://doi.org/10.1006/jsvi.2001.3984.

Kim, B.S.; S.H. Lee.; M. G. Lee.; J. Ni.; J.Y. Song.; C.W. Lee. (2007). A comparative study on damage detection in speed-up and coast-down process of grinding spindle-typed rotor-bearing system. Journal of Materials Processing Technology,187-188,30-36.

doi:https://doi.org/10.1016/j.jmatprotec.2006.11.222

Muhammad, A. and Ibrahim, H. S. (2018). Strength analysis and structural optimization of an 1-shaped bracket. Nigerian Journal of Technological Research, 13(2):14-19.

Muhammad, A. and Ibrahim, H. S. (2018). Weight Optimization of a Laboratory Stool Using Ansys Workbench. Paper presented at 1 st International Civil Engineering Conference (ICEC 2018), Minna, Nigeria, 14-21: FUT Minna.

Muhammad, A. and Ibrahim, H. S. (2018). Structural Analysis of a Knuckle Joint using different materials. Paper presented at 1st International Civil Engineering Conference (ICEC 2018), Minna, Nigeria, 100-106: FUT Minna.

Muhammad, A. and Ibrahim, H. S. (2019). Static Analysis and Optimization of a Connecting Rod. International Journal of Engineering Technology and Science (IJETS), 6(1): $24-40$.
Muhammad, A. and Ibrahim, H. S. (2019). Transient Analysis and Optimization of a Knuckle Joint. KINETIK, 4(2): 179-186.

Nipun. (2015, 10 14). Difference Between Yield Strength and Tensile Strength. Retrieved from Pediaa: http://pediaa.com/difference-between-yield-strength-andtensile-strength/

Qiongying, L. Y. M. (2014). Modal analysis of a magnetic climbing wall car frame based on the ANSYS. 2014 IEEE Workshop on Electronics, Computer and Applications (IWECA) (pp. 938-940). Ottawa, ON, Canada: IEEE. doi:10.1109/IWECA.2014.6845775.

Scientific R. (2021). Laboratory Aids, Standard, Heavy, Triangular, A-Base, and Plastic Support Stands with Rods. (Rose Scientific Ltd) Retrieved 8 2, 2021, from https://www

Stanley, C. and Valiulis, R. I. (2002). United States Patent No. US 6,367,749 B2.\#

Wang, G.; G. Zhou.; J. Yang.; Y. Guan.; W. Gong.; H. Zhang. (2012, July). Modal analysis of high-speed spindle based on ANSYS. 2012 7th International Conference on Computer Science \& Education (ICCSE); 475-478. Melbourne, VIC, $\quad$ Australia: IEEE. doi:10.1109/ICCSE.2012.6295117

Xiaolin, C. (2014). Finite Element Modeling and Simulation with ANSYS Workbench. London New York: CRC Press. 